\title{
When steroids are not enough in immune-related hepatitis: current clinical challenges discussed on the basis of a case report
}

\author{
Marie-Léa Gauci (D , , ${ }^{1,3}$ Barouyr Baroudjian, ${ }^{3}$ Celeste Lebbe, ${ }^{1,2,3}$ Olivier Roux ${ }^{4}$
}

To cite: Gauci M-L,

Baroudjian B, Lebbe C, et al. When steroids are not enough in immune-related hepatitis: current clinical challenges discussed on the basis of a case report. Journal for ImmunoTherapy of Cancer 2021;9:e002337. doi:10.1136/ jitc-2021-002337

Accepted 07 January 2021

\section{Linked}

http://dx.doi.org/10.1136/ jitc-2021-002391.R1

\section{Check for updates}

(C) Author(s) (or their employer(s)) 2021. Re-use permitted under CC BY-NC. No commercial re-use. See rights and permissions. Published by BMJ.

${ }^{1}$ U976, INSERM, Paris, Île-deFrance, France

${ }^{2}$ Université Paris Diderot-Paris VII, Université Sorbonne Paris Cité, Paris, Île-de-France, France ${ }^{3}$ AP-HP, Département de Dermatologie, Hôpital SaintLouis, Paris, Île-de-France,

France

${ }^{4}$ Service d'hépatologie et réanimation hépatique, $\mathrm{DMU}$ DIGEST, AP-HP Nord, Hôpital Beaujon, Clichy, France

Correspondence to

Dr Marie-Léa Gauci; marie-lea.gauci@aphp.fr

\section{ABSTRACT}

Immune-related hepatitis (IRH) is a frequent but poorly understood immune-related adverse event and its frequency increases since the use of combination therapy in several cancer types. Therefore, there is an urgent need to develop adapted guidelines to manage IRH.In the present letter, based on Ziogas et al report entitled 'When steroids are not enough in immune-related hepatitis: current clinical challenges discussed on the basis of a case report', several points are discussed: assessment of IRH severity and liver biopsy indication, immune-related cholangitis as a differential diagnosis for some IRH presentation, the need of steroids for IRH management or the indication for second line immunosuppressive treatment and finally, the possibility of immunotherapy resumption.

\section{Dear Editor,}

We read with interest the recent report about immune-related hepatitis (IRH) published by Ziogas et $a l^{1}$ in the Journal for ImmunoTherapy of Cancer under the title 'When steroids are not enough in immunerelated hepatitis: current clinical challenges discussed on the basis of a case report'.

IRH is a frequent but poorly understood immune-related adverse event and its frequency increases since the use of combination therapy in several cancer types. Therefore, there is an urgent need to develop adapted guidelines to manage IRH.

Although the authors proposed several therapeutic strategies for IRH management based on their experience and current guidelines, we have the following concerns and questions:

\section{IRH SEVERITY DIAGNOSIS AND BIOPSY INDICATION}

IRH severity should not be appreciated using CTCAE classification for transaminase increase as it may overestimate the severity of the disease. This is particularly true when it is compared with the Drug-Induced Liver Injury Network (DILIN) classification. ${ }^{2} 3$ Indeed, the value of transaminase is not a marker of severity in patients with acute hepatitis, especially in patients with drug-induced liver injury. It remains true in patients with IRH as no association between the degree of lobular damage and the CTCAE grade of transaminase elevation has been demonstrated. ${ }^{4}$ Therefore, IRH management should not be based on CTCAE grade but based on severity criteria attesting the liver function: prothrombin time (PT) and bilirubin level recently proposed by our team and others. $^{2}{ }^{3}$ In the presented case of IRH, PT value was not reported but the patient developed severity criteria through bilirubin level increase. Interestingly, the patient presented an important inflammatory reaction with fever, and an increased CRP level and white blood cell count. To our knowledge, there is no evidence of an association between clinical or biological abnormalities and the development of IRH severity criteria.

The authors decided not to perform a liver biopsy because of hemorrhagic risk. In patients with hemostatic disorders, a transjugular liver biopsy is safe. ${ }^{5}$ Moreover, the liver biopsy may confirm the diagnosis of IRH, but may also exclude a differential diagnosis: liver infiltration from melanoma should be ruled out as the presentation is classically an acute liver failure with jaundice and hepatomegaly. It is also important to define the patterns of IRH: The main presentation associates lobular and portal inflammation with lobular granulomas in patients treated with ipilimumab. ${ }^{26}$ However, other histological features have been described, such as cholangitis. It is yet not clear whether the management may remain the same between these two entities; therefore, we recommend performing a liver biopsy especially in patients with jaundice. 


\section{WHAT ABOUT A POSSIBLE IMMUNE RELATED CHOLANGITIS IN THIS CASE REPORT?}

Although there is actually no clear diagnostic criteria for immune-related cholangitis, it could be suspected in the presented case because of the jaundice. ${ }^{1}$

Immune-related cholangitis is a rare immune-related adverse event that affects $0 \%-4.5 \%$ of patients treated with PD-1 inhibitors. In the literature, few cases are described. ${ }^{7}$

It seems to occur after a median of 5 cycles (range: 2-24) of anti-PD-1 infusion, with $30.0 \%$ of cases occurring after more than 10 cycles of treatment. ${ }^{8}$

In the comprehensive literature review of immunerelated cholangitis cases recently published by Onoyama $e t$ $a l,{ }^{7}$ biliary stenosis occurred in $34.8 \%(8 / 23)$ and stenosis in the intrahepatic biliary tract in $30.0 \%(7 / 23)$; biliary dilation was observed in $76.9 \%(20 / 26)$ and hypertrophy of the biliary tract in $95.2 \%(20 / 21)$ of cases. Therefore, Onoyama et al classified immune-related cholangitis in three types: intrahepatic type, extrahepatic type and diffuse type. However, it seems difficult in distinguishing nivolumab-induced cholangitis from other hepatobiliary diseases using imaging results. ${ }^{8}$

Histopathological findings for immune-related cholangitis revealed inflammatory changes in the bile duct and/or peribiliary tract and the inflammatory cells are mostly $\mathrm{CD}^{+} \mathrm{T}$ cells. Lobular hepatitis was rarely found ${ }^{7}$ which might distinguish IRH and immune-related cholangitis.

Immune-related cholangitis seems to be a steroidresistant entity, except for the intrahepatic type which appears to respond to steroids. ${ }^{7}$ Therefore, steroids are usually not recommended for immune-related cholangitis. In case of minimal/no elevation in transaminases and without increased bilirubin, De Martin et al proposed ursodeoxycholic acid treatment alone as first-line treatment and steroids should be added if liver tests worsen or do not improve. There are few reports regarding cholangitis treated with other immunomodulatory medications, except for two patients who received mycophenolate mofetil (MMF) efficiently. ${ }^{8}$

The efficiency for tacrolimus administration observed in this interesting case ${ }^{1}$ could open a new perspective of efficient treatment in such immune-related adverse event.

\section{IRH MANAGEMENT: STEROIDS ARE NOT ALWAYS NEEDED FOR GRADE $\geq 3$ IRH}

Steroids must definitively not be empirically introduced for all grade $\geq 3$ IRH and could be guided by liver severity parameters (PT value, bilirubin level) or severity of histology damage. ${ }^{2}{ }^{3}$ Indeed, our team and others reported spontaneous resolution of grade $\geq 3$ IRH that did not present degradation of PT value and bilirubin, and time for IRH resolution was no longer without steroids. ${ }^{2}$ Therefore, in these cases, close monitoring of liver biological parameters must be encouraged. ${ }^{3}$

\section{ARE STEROIDS NEEDED FOR GRADE $\geq 3$ IRH THAT ARE ASSOCIATED WITH ACUTE LIVER FAILURE?}

First of all, it is important to note that corticosteroid use in DILIN-related acute liver failure has been shown to be harmful. ${ }^{9}$ Then, no clinical trial has been designed to evaluate the need for steroid administration in case of IRH with acute liver failure. Finally, there is no correlation between pathological liver damage and steroid response or second-line immunosuppressor, ${ }^{4}$ Therefore, with the actual IRH knowledge, De Martin et al and our team suggested to initiate steroids in case of IRH with severity criteria at $0.5-1 \mathrm{mg} / \mathrm{kg} /$ day. $^{2}{ }^{3}$ Interestingly, steroids did not seem to impair anti-tumor response, probably because this evaluation was performed for patients who mostly presented severe criteria for IRH and, thus initiated a strong anti-tumor response. ${ }^{2}$

In the presented case, there was a rapid therapeutic escalation leading to the introduction of a tritherapy based on steroids MMF and tacrolimus. ${ }^{1}$ Although this treatment escalation allowed the improvement of biological liver parameters, ${ }^{1}$ De Martin $e t a \hat{l}$ proposed to monitor biological liver parameter during 7 days after steroid initiation, to avoid too fast immunosuppression escalation. ${ }^{3}$

\section{WHAT CAN WE DO WHEN BIOLOGICAL LIVER PARAMETERS WORSEN DESPITE STEROIDS INITIATION AND INCREASED DOSE?}

In our cohort, ${ }^{2}$ none of the patients required second-line therapy for the IRH. Therefore, it seems to be an exceptional situation. The present paper addresses tacrolimus' proposition as second-line therapy for severe IRH which are steroid and MMF resistant. Because of histopathological and immunostaining findings of liver biopsies, ${ }^{2}$ there is a strong rational to use anti-lymphocyte immunosuppressive drugs such as MMF and tacrolimus. However, their use could impair lymphocytes' anti-tumor response as presented in this case. They should be initiated only in case of steroid escalation failure during a week of follow-up, ${ }^{1}$ otherwise for life-threatening toxicity.

\section{WHAT ABOUT IMMUNOTHERAPY RESUMPTION?}

Several research published immunotherapy resumption for patients who presented high-grade IRH. ${ }^{6}$ In our cohort of 21 patients who experienced grade $\geq 3 \mathrm{IRH}^{2},{ }^{2}$ immunotherapy was resumed for 8 patients based on risk-benefit balance, with a median time of 141 days (IQR: 45-158; 4.7 months). The same immunotherapy for two patients $(9.5 \%)$ and another class of immunotherapy for the six remaining patients $(28.6 \%)$, including four patients who received steroids. There was no case of IRH relapse, and no administration of low-dose steroids to prevent IRH recurrence. ${ }^{2}$ Therefore, based on the risk-benefit balance, immunotherapy may be resumed without severe IRH relapse.

In conclusion, although several strategies were proposed to manage IRH efficiently, further controlled trials are 
needed to increase IRH knowledge and uniformly drive their management.

Contributors All authors drafted, read and approved this letter: M-LG, BB, CL and OR. Funding The authors have not declared a specific grant for this research from any funding agency in the public, commercial or not-for-profit sectors.

Competing interests None declared.

Patient consent for publication Not required.

Provenance and peer review Commissioned; internally peer reviewed.

Open access This is an open access article distributed in accordance with the Creative Commons Attribution Non Commercial (CC BY-NC 4.0) license, which permits others to distribute, remix, adapt, build upon this work non-commercially, and license their derivative works on different terms, provided the original work is properly cited, appropriate credit is given, any changes made indicated, and the use is non-commercial. See http://creativecommons.org/licenses/by-nc/4.0/.

\section{ORCID iD}

Marie-Léa Gauci http://orcid.org/0000-0003-3081-9810

\section{REFERENCES}

1 Ziogas DC, Gkoufa A, Cholongitas E, et al. When steroids are not enough in immune-related hepatitis: current clinical challenges discussed on the basis of a case report. $J$ Immunother Cancer 2020;8:e001322.

2 Gauci M-L, Baroudjian B, Bédérède U, et al. Severe immunerelated hepatitis induced by immune checkpoint inhibitors: clinical features and management proposal. Clin Res Hepatol Gastroenterol 2020:101491.

3 De Martin E, Michot J-M, Rosmorduc O, et al. Liver toxicity as a limiting factor to the increasing use of immune checkpoint inhibitors. JHEP Rep 2020;2:100170.

4 Cohen J V, Dougan M, Zubiri L. Liver biopsy findings in patients on immune checkpoint inhibitors. Mod Pathol 2020.

5 Lavian JD, Thornton LM, Zybulewski A, et al. Safety of percutaneous versus transjugular liver biopsy: a propensity score matched analysis. Eur J Radiol 2020;133:109399.

6 De Martin E, Michot J-M, Papouin B, et al. Characterization of liver injury induced by cancer immunotherapy using immune checkpoint inhibitors. J Hepatol 2018;68:1181-90. doi:10.1016/j. jhep.2018.01.033

7 Onoyama T, Takeda Y, Yamashita T, et al. Programmed cell death-1 inhibitor-related sclerosing cholangitis: a systematic review. World $J$ Gastroenterol 2020;26:353-65.

8 Izumi H, Kodani M, Kurai J, et al. Nivolumab-induced cholangitis in patients with non-small cell lung cancer: case series and a review of literature. Mol Clin Oncol 2019;11:439-46.

9 Karkhanis J, Verna EC, Chang MS, et al. Steroid use in acute liver failure. Hepatology 2014;59:612-21. 